\title{
Time dependent effects of stress prior to encoding on event-related potentials and $24 \mathrm{~h}$ delayed retrieval
}

Citation for published version (APA):

Quaedflieg, C. W. E. M., Schwabe, L., Meyer, T., \& Smeets, T. (2013). Time dependent effects of stress prior to encoding on event-related potentials and $24 \mathrm{~h}$ delayed retrieval. Psychoneuroendocrinology, 38(12), 3057-3069. https://doi.org/10.1016/j.psyneuen.2013.09.002

Document status and date:

Published: 12/09/2013

DOI:

10.1016/j.psyneuen.2013.09.002

Document Version:

Publisher's PDF, also known as Version of record

Document license:

Taverne

Please check the document version of this publication:

- A submitted manuscript is the version of the article upon submission and before peer-review. There can be important differences between the submitted version and the official published version of record.

People interested in the research are advised to contact the author for the final version of the publication, or visit the DOI to the publisher's website.

- The final author version and the galley proof are versions of the publication after peer review.

- The final published version features the final layout of the paper including the volume, issue and page numbers.

Link to publication

\footnotetext{
General rights rights.

- You may freely distribute the URL identifying the publication in the public portal. please follow below link for the End User Agreement:

www.umlib.nl/taverne-license

Take down policy

If you believe that this document breaches copyright please contact us at:

repository@maastrichtuniversity.nl

providing details and we will investigate your claim.
}

Copyright and moral rights for the publications made accessible in the public portal are retained by the authors and/or other copyright owners and it is a condition of accessing publications that users recognise and abide by the legal requirements associated with these

- Users may download and print one copy of any publication from the public portal for the purpose of private study or research.

- You may not further distribute the material or use it for any profit-making activity or commercial gain

If the publication is distributed under the terms of Article $25 \mathrm{fa}$ of the Dutch Copyright Act, indicated by the "Taverne" license above, 


\title{
Time dependent effects of stress prior to encoding on event-related potentials and $24 \mathrm{~h}$ delayed retrieval
}

\author{
Conny W.E.M. Quaedflieg ${ }^{a, *}$, Lars Schwabe ${ }^{b}$, \\ Thomas Meyer ${ }^{a}$, Tom Smeets ${ }^{a}$
}

${ }^{a}$ Faculty of Psychology and Neuroscience, Maastricht University, Maastricht, The Netherlands

${ }^{\mathrm{b}}$ Department of Cognitive Psychology, Ruhr-University Bochum, 44780 Bochum, Germany

Received 1 May 2013; received in revised form 2 September 2013; accepted 3 September 2013

\section{KEYWORDS \\ Emotional memory; Event-related potential (ERP); \\ Glucocortiocoids (GCs); \\ Late positive potentials (LPP); Maastricht Acute Stress Test (MAST)}

\begin{abstract}
Summary Stress can exert profound effects on memory encoding. Here, we investigated whether (sub)cortical information processing during encoding and memory retrieval at a $24 \mathrm{~h}$ delayed test are affected by the temporal proximity between stress and memory encoding. Sixtyfour participants engaged in the Maastricht Acute Stress Test (MAST) or a no-stress control condition either immediately before (i.e., proximate condition) or $30 \mathrm{~min}$ before (i.e., distant condition) a picture encoding task. In general, stress decreased the number of freely recalled and recognized pictures and increased the number of false alarms. However, timing of stress exposure did not differentially affect picture recall, recognition or selective attention processes (i.e., LPP). Nevertheless, stress-induced cortisol responses and correctly recognized neutral pictures were positively associated within the proximate stress condition but negatively associated within the distant stress condition. These findings suggest that the time at which a stressor is applied might differentially impact the association between stress-induced cortisol elevations and memory formation and indicate the need for a finer delineation of the time window during which glucocorticoids affect memory formation processes.
\end{abstract}

(C) 2013 Elsevier Ltd. All rights reserved.

\footnotetext{
* Corresponding author at: Faculty of Psychology and Neuroscience, Maastricht University, P.O. Box 616, 6200 MD Maastricht, The Netherlands. Tel.: +31 43 3884536; fax: +31 433884196 .

E-mail address: conny.quaedflieg@maastrichtuniversity.nl (C.W.E.M. Quaedflieg).
}

\section{Introduction}

When confronted with a stressful situation, our brain activates two physiological systems that allow us to cope effectively with the stressor. The rapidly acting autonomic nervous system (ANS) results in adrenaline and noradrenaline release and increased arousal, alertness and focused attention. A second, slower mechanism involves the activation of the hypothalamic-pituitary-adrenal (HPA) axis that results in 
the secretion of the primary human glucocorticoid (GC) cortisol, which can bind to mineralocorticoid or glucocorticoid receptors (MRs and GRs, respectively; e.g., de Kloet et al., 2005). The binding of cortisol to MRs and GRs in limbic structures, such as for example the hippocampus and amygdala, activates mechanisms involved in hippocampal plasticity and thereby can modulate memory processes (e.g., McGaugh and Roozendaal, 2002; Roozendaal et al., 2009; Joëls et al., 2011). Moreover, an interaction of GCs with the noradrenergic system in the basolateral nucleus of the amygdala (BLA; e.g. Roozendaal et al., 2009; Roozendaal and McGaugh, 2011), a structure essential for the formation of emotional memories (LeDoux, 2000), is said to be crucial for stress to affect emotional memory.

This stress-related release of GCs and noradrenaline influences the quantity and quality of memory (Schwabe et al., 2010). The effects of GCs seem to be moderated by the memory phase that is targeted by stress and the emotional arousal elicited by the learned material (Wolf, 2009; Schwabe et al., 2012). In particular, stress can facilitate memory consolidation (e.g., Cahill et al., 2003; Smeets et al., 2008), whereas stress before retention testing typically impairs memory retrieval (e.g., de Quervain et al., 1998; Kuhlmann et al., 2005). Moreover, these effects are more pronounced for emotionally arousing material than for neutral stimuli (Cahill et al., 2003; Kuhlmann et al., 2005; see for review of animal studies Roozendaal and McGaugh, 2011). It has also been suggested that during memory formation, the exact temporal dynamics of GCs and noradrenaline release relative to the emotional memory encoding task are crucial for enhanced consolidation (e.g., Joëls et al., 2006; Diamond et al., 2007). Specifically, emotional experiences initiate a rapid enhancement of hippocampal neuroplasticity that is mediated by the amygdala and followed by stress-related GC enhancement of hippocampal neuroplasticity via non-genomic membrane MR activity (Joëls et al., 2008; Karst et al., 2010). Over time, genomic GR actions induce a refractory state of the hippocampus, thereby impairing the processing of new information (Joëls et al., 2006; Diamond et al., 2007; Karst et al., 2010; Joëls et al., 2011). Support for this idea comes from a study by Zoladz et al. (2011), who found that stress applied immediately before encoding enhanced recognition of positive words while stress applied 30 min before encoding impaired recall of negative words $24 \mathrm{~h}$ later.

One way to further test the time-dependent stress effect on memory formation is to use event related potentials (ERPs) obtained from electroencephalography (EEG). For instance, the time course of memory and emotion processes has been investigated with the late positive potential (LPP), an ERP over centro-parietal sites between 300 and $700 \mathrm{~ms}$ (e.g., Hajcak et al., 2012; Wilding and Ranganath, 2012). The amplitude of the LPP appears to be larger for remembered stimuli (i.e., the 'subsequent memory effect'), especially when it concerns emotional material (Cuthbert et al., 2000; Dolcos and Cabeza, 2002; Olofsson et al., 2008). Weymar et al. (2012) recently used ERPs to investigate the effects of pre-learning stress on neutral and unpleasant picture recall $24 \mathrm{~h}$ later. Although stress did not affect memory performance overall, the amplitude of the LPP during encoding of unpleasant pictures correlated positively with recall performance of unpleasant pictures $24 \mathrm{~h}$ later in the stress, but not the control group. This suggests that pre-learning stress sensitizes the brain toward enhanced selective attention to unpleasant stimuli.

The current study draws upon the work of Weymar et al. (2012) and Zoladz et al. (2011) in that it investigated whether exposure to acute stress immediately (i.e., proximate stress group) or 30 min (i.e., distant stress group) before learning differentially affects emotional memory processing. This effect was assessed at the electrophysiological level by means of the LPP generated during memory encoding, and behaviourally using a delayed memory test that was carried out $24 \mathrm{~h}$ later. Given the known involvement of cortisol in the memory enhancing effects of stress on memory consolidation (e.g., Smeets et al., 2008), we also sampled salivary cortisol throughout the encoding session and related the stress-induced cortisol elevation to LPPs and $24 \mathrm{~h}$ delayed memory performance. Based on the theoretical framework of timing (Joëls et al., 2006), brain systems (Roozendaal et al., 2006), and previous work in humans (Zoladz et al., 2011; Weymar et al., 2012), it was hypothesized that stress applied immediately before learning would improve $24 \mathrm{~h}$ delayed recall and recognition of emotional stimuli through enhanced selective attention (i.e., larger LPPs) and elevated cortisol levels, relative to a no-stress control condition. The opposite pattern of findings was expected for stress applied $30 \mathrm{~min}$ before learning.

\section{Methods}

\subsection{Participants}

Sixty-four right-handed healthy male undergraduates (mean age $=21.25$ years, $S D=2.5$; range: $18-31$ years) were recruited to participate in this study via advertisements at Maastricht University. Participants were excluded if they had a history of psychiatric, neurologic, cardiovascular or neuroendocrine diseases, were considered heavy smokers (i.e., more than 15 cigarettes/day), used medication known to affect the ANS or HPA axis, were regular drug users, or had a

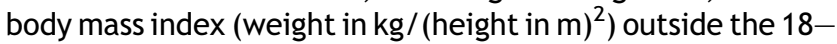
30 range. Test protocols were approved by the standing ethics committee of the Faculty of Psychology and Neuroscience, Maastricht University. All participants signed a written informed consent and were given a small reward (course credit or monetary) in return for their participation.

\subsection{Stress manipulation}

The Maastricht Acute Stress Test (MAST; Smeets et al., 2012) is a concise and valid procedure to reliably elicit robust subjective, autonomic and glucocorticoid stress responses. It consists of a 5 min preparation phase in which the task is explained and a 10 min acute stress phase that includes several exposures to cold pressor stress and various mental arithmetic challenges along with social-evaluative pressure (i.e., negative feedback). Specifically, in 5 trials that varied in duration from 60 to $90 \mathrm{~s}$, participants immersed their hand into ice water $\left(2{ }^{\circ} \mathrm{C}\right.$; plexiglas box with an electrical cooler and a circulation pump from JULABO Labortechnik, Seelbach, Germany). In between the hand immersion trials, participants engaged in mental arithmetic challenges in which they had to count backwards as fast and accurately as possible in steps of 17 starting at 2043 for 45,60 or 90 s. Whenever they 
counted too slowly or made a mistake, they received negative feedback (i.e., to count faster or start over again at 2043). To increase unpredictability and uncontrollability, participants were told that the order and duration of the hand immersion and mental arithmetic trials would be randomly chosen by the computer and that they would be videotaped for later analyses of their facial expressions, a procedure for which they had to provide written consent (for more information see Smeets et al., 2012).

In the no-stress control condition, participants immersed their hand in lukewarm water $\left(35-37^{\circ} \mathrm{C}\right)$ and in between the hand immersion trials, performed a simple arithmetic task in which they had to count consecutively from 1 to 25 at their own pace and had to start anew at 1 when having reached 25. No feedback was given and participants were not videotaped. The duration and order of hand immersion and arithmetic trials paralleled that of the MAST (see Smeets et al., 2012; Study 3).

\subsection{Subjective and neuroendocrine stress responses}

\subsubsection{Subjective stress}

Subjective stress prior to and immediately following the MAST was assessed using the Negative Affect subscale of the Positive and Negative Affect Schedule, state version (PANAS; Watson et al. , 1988). The PANAS consists of two subscales that quantify current positive affect (PA) and negative affect (NA) using 5point scales (anchors: 1 = very slightly or not at all; 5 = extremely). Higher scores on the NA scale are indicative of higher levels of experienced negative affect.

\subsubsection{Salivary cortisol}

Neuroendocrine stress measures prior to and in response to the MAST were obtained with synthetic Salivette (Sarstedt ${ }^{\mathbb{R}}$, Etten-Leur, The Netherlands) devices 5 min before ( $\left.t_{\text {pre-stress }}\right)$ and 4 times after the MAST $\left(t_{+0}, t_{+20}, t_{+40}, t_{+50 \mathrm{~min}}\right.$ with reference to the end of the stressor). Samples were stored at $-20{ }^{\circ} \mathrm{C}$ until cortisol levels were determined by a commercially available luminescence immune assay kit (IBL, Hamburg, Germany). Mean intra- and inter-assay coefficients of variation are typically less than $5 \%$, and the lower and upper detection limits were $0.015 \mathrm{mg} / \mathrm{dl}(0.41 \mathrm{nmol} / \mathrm{l})$ and $4.0 \mathrm{mg} /$ dl $(110.4 \mathrm{nmol} / \mathrm{l})$, respectively.

\subsection{Memory task}

During the encoding phase, participants were presented with 36 negative and 36 neutral pictures from the International Affective Picture System (IAPS; Lang et al. , 2008; see Appendix 1) on a monitor $(48 \mathrm{~cm} \times 27 \mathrm{~cm})$. The pictures belonged to one of the following five categories: person/action (e.g., neutral: woman answering phone; negative: carjacking), objects (e.g., neutral: clock; negative: collection skulls), scenes (e.g., neutral: sunset at beach, negative: tornado), animals (e.g., neutral: butterfly on flower; negative: dog growling) or objects/ action (e.g., neutral: chess game; negative: F1 car explosion). Pictures were presented for $3 \mathrm{sec}$ in full size $(38 \mathrm{~cm} \times 27 \mathrm{~cm})$ on black background, followed by a $50 \%$ size presentation of that image during which individual valence and arousal ratings were obtained by means of the Self-Assessment Manikin (SAM;
Lang et al., 2008) procedure to ensure deep picture encoding. The $50 \%$ picture was presented until the participant responded. An interstimulus interval of $2 \mathrm{~s}$, during which a fixation cross was presented, was applied between all stimuli. IAPS pictures were chosen according to the IAPS valence and arousal ratings (neutral pictures: valence $M=5.84$, arousal $M=3.88$; negative pictures: valence $M=3.23$, arousal $M=5.50)$. The ratings of the pictures obtained in the current sample were similar to the normative IAPS ratings (neutral pictures: valence $M=6.09$, arousal $M=4.06$; negative pictures: valence $M=2.90$, arousal $M=5.73$ ).

The recognition picture set presented $24 \mathrm{~h}$ later consisted of 72 pictures, of which $50 \%$ were old pictures, $25 \%$ were IAPS pictures not presented in the encoding task and were conceptually related to the old pictures (new similar/related neutral pictures) and $25 \%$ were new/different pictures (i.e., not previously presented and conceptually different). The new similar and new different pictures were matched to the old pictures on emotional valence and arousal (new similar/ related neutral pictures: valence $M=6.01$, arousal $M=3.76$; negative pictures: valence $M=3.12$, arousal $M=5.71$; new/ different neutral pictures: valence $M=5.69$, arousal $M=3.79$; negative pictures: valence $M=3.35$, arousal $M=5.45$ ). Performance on the recognition task was defined by hits (reflecting correct detection of old pictures), false alarms ( $F A$; reflecting incorrect detection of new pictures as being old), the discrimination index (Pr; reflecting correct discrimination of new from old pictures, i.e. (\# hits $+0.5 / \#$ old targets +1$)-(\#$ false alarms $+0.5 / \#$ new targets +1$)$; Snodgrass and Corwin, 1988), and the bias index (Br; \# false alarms $+0.5 / \#$ new targets +1$) /(1-P r)$; Snodgrass and Corwin, 1988). To avoid mood state induction, the presentation order of the pictures was semi-randomized so that no more than three pictures of one condition appeared consecutively in the picture encoding and the recognition part of the task.

\subsection{Design and procedure}

A 2 (Condition: stress vs. control) $\times 2$ (Timing: proximate vs. distant) $\times 2$ (Picture Type: neutral vs. negative) mixedmodel was employed, with Condition and Timing as between-subjects factors and Picture type as within subjects factor. Participants were randomly assigned to one of the four conditions and all testing took place between 12:30 and 18:00 h to control for the circadian rhythm of cortisol. Participants were asked to refrain from eating, exercising extensively or drinking anything but non-sparkling water for $2 \mathrm{~h}$ prior to both experimental sessions.

A timeline of the experimental sessions is displayed in Fig. 1. After their arrival in the laboratory, participants received information on the experimental procedure and gave written consent to participate in this study. Next, a saliva sample was taken with the explicit instruction that this sample would be immediately assayed to check whether they had adhered to our instructions not to eat, drink, etc. In reality, the sample was simply destroyed without being analyzed. This was done to increase truth-telling behavior when they were subsequently asked whether they had in fact adhered to the instructions. Next, participants were asked to drink $200 \mathrm{ml}$ of apple juice to standardize glucose levels (Kudielka et al., 2007). Next, EEG equipment was prepared and an 8 min baseline EEG activity was measured (baseline 
Day 1

Day 2

Distant Stress/Control (30min before encoding)

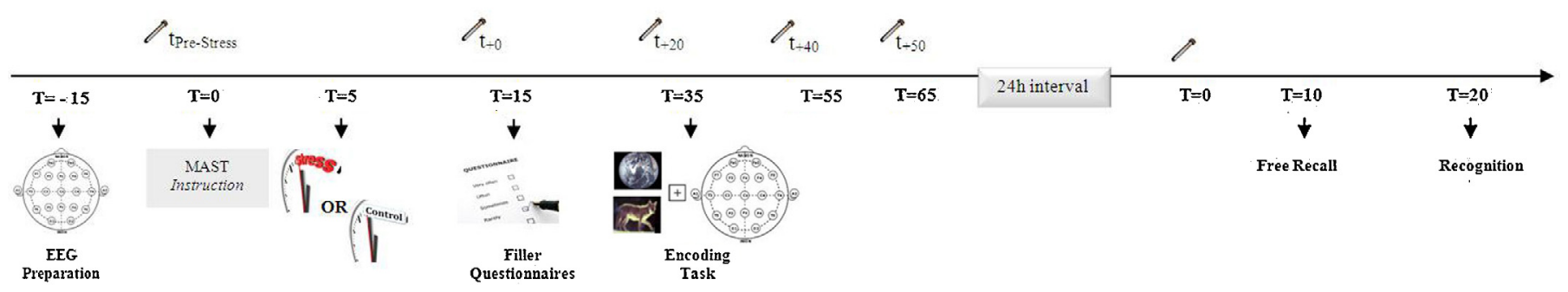

Proximate Stress/Control (immediately before encoding)

\begin{tabular}{|c|c|c|c|c|c|c|c|c|c|c|}
\hline & tpre-Stress & & $\mathrm{t}_{-0}$ & $l_{t_{-20}}$ & $l_{t-40}$ & $Z_{t+50}$ & & $D$ & & \\
\hline$T=-15$ & $\mathrm{~T}=0$ & $T=5$ & $T=15$ & $\mathrm{~T}=35$ & $\mathrm{~T}=55$ & $\mathrm{~T}=65$ & $24 \mathrm{~h}$ interval & $\mathbf{T}=0$ & $\mathrm{~T}=10$ & $\mathrm{~T}=\mathbf{2 0}$ \\
\hline$\downarrow$ & $\downarrow$ & $\downarrow$ & $\downarrow$ & $\downarrow$ & & & & & $\downarrow$ & $\downarrow$ \\
\hline 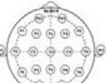 & $\begin{array}{l}\text { MAST } \\
\text { Instruction }\end{array}$ & & & & & & & & Free Recall & Recognition \\
\hline $\begin{array}{c}\text { EEG } \\
\text { Preparation }\end{array}$ & & & $\begin{array}{c}\text { Encodir } \\
\text { Task }\end{array}$ & $\begin{array}{r}\text { Fill } \\
\text { Question }\end{array}$ & & & & & & \\
\hline
\end{tabular}

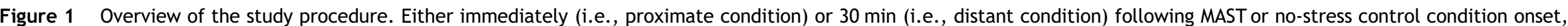
participants performed the memory encoding task. Abbreviations: MAST, Maastricht Acute Stress Test. 
EEG data are not reported here). After assessing baseline Negative Affect (PANAS) and baseline cortisol ( $\left.t_{\text {pre-stress }}\right)$, the MAST or its control counterpart was performed. Either immediately (i.e., proximate condition) or $30 \mathrm{~min}$ (i.e., distant condition) following the MAST or no-stress control condition onset, participants performed the memory encoding task. Participants were told that we were interested in the individual differences in emotional reactivity raised by the pictures and that the responses would be evaluated the next day. They were instructed to rate the pictures based on arousal and valence using the SAM. Filler questionnaires were used to bridge the time intervals. Participants in the distant groups filled the questionnaires out in between the stress induction and the encoding task while participants in the proximate group filled them out after the encoding task. After administration of the MAST or no-stress control condition, the PANAS and again 8 min baseline EEG activity were assessed. Participants were asked to provide additional saliva samples at 4 time points following the MAST or no-stress control condition: at $t_{+0}, t_{+20}, t_{+40}, t_{+50 \mathrm{~min}}$ with reference to the end of the stressor.

Twenty-four hours after the encoding session, participants returned to the lab. After a rest period of $10 \mathrm{~min}$, a baseline saliva sample was obtained. Next, the participants had to complete the surprise free recall and recognition test. In the free recall test, participants were given 10 min to write down all pictures they could remember from the picture presentation procedure the day before. Participants were instructed to provide enough details so that two independent raters could identify and discriminate the picture from similar pictures. For the recognition test, participants were instructed to classify each picture as old or new. After all measures were completed, participants were debriefed and thanked for their participation.

\subsection{EEG data acquisition and analysis}

Electroencephalography (EEG) measurements were obtained during the encoding task, using 19 electrodes (F7, F3, Fz, F4, F8, C3, Cz, C4, CP1, CPz, CP2 P3, P1, Pz, P4, P2, 01, Oz, O2) attached to an elastic cap and a right mastoid according to the international 10-20 system. Two electrodes at the outer canthi of both eyes recorded horizontal eye movements and two electrodes above and below the left eye recorded vertical eye movements. The ground was located at AFz and the reference electrode was placed on left mastoid. A $500 \mathrm{~Hz}$ sampling rate and a band pass filter of $0.01-30 \mathrm{~Hz}$ was used to record EEG using Vision Recorder (Brain Products, Germany). Scalp-electrode impedance was kept below $5 \mathrm{k} \Omega$ to ensure high-quality EEG recordings. Offline analyses were performed with Vision Analyzer 2.0 (Brain Products, Germany), including referencing to computer-linked mastoids reference, EOG correction using the Gratton and Coles algorithm and baseline correction of $200 \mathrm{~ms}$ before stimulus onset. Epochs were made for each stimulus type separately from $200 \mathrm{~ms}$ before stimulus onset to $3000 \mathrm{~ms}$ after stimulus onset. Epochs containing EEG changes exceeding $75 \mu \mathrm{V}$ were automatically omitted from averages. Subjects were only included in the EEG analysis if they had at least 16 artifactfree trials per condition (average number of trials was 27.3 for neutral and 27.2 for negative pictures). Data from two participants were excluded due to excessive artifacts and data of another participant were lost due to technical problems. The LPP was determined as the mean ERP amplitude in the window of 500-1000 ms over centro-parietal electrodes (CP1, CPz, CP2, P1, Pz, P2).

\subsection{Data analysis}

Subjective stress ratings were analyzed using a 2 (Condition: stress vs. control) $\times 2$ (Timing: proximate vs. distant) $\times 2$

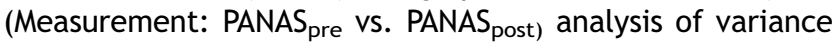
(ANOVA) with the latter as within subject factor. Cortisol data were log-transformed before analysis as Shapiro-Wilk tests of normality showed typical skewness of the data. Cortisol responses were analyzed using a 2 (Condition: stress vs. control) $\times 2$ (Timing: proximate vs. distant) $\times 5$ (Measurement: $t_{\text {pre-stress }}$ vs. $t_{+0}$ vs. $t_{+20}$, vs. $t_{+40}$ vs. $t_{+50 \mathrm{~min})}$ ANOVA. For descriptive purposes, a responder rate was calculated representing participants with a cortisol increase equal to or larger than $2.5 \mathrm{nmol} / \mathrm{l}$ (see, for example, Kirschbaum et al., 1993; Smeets et al., 2012), which is thought to reflect a cortisol secretory episode (van Cauter and Refetoff, 1985). The percentage of participants who could be classified as cortisol responders (i.e., a cortisol increase $\geq 2.5 \mathrm{nmol} / \mathrm{l}$; see above) was $75 \%$ (12 out of 16 ) for the proximate stress group and $81 \%$ (13 out of 16) for the distant stress group. One participant out of 16 in the proximate control group showed a cortisol increase of $8.8 \mathrm{nmol} / \mathrm{l}$ and was excluded from further analyses. For each participant individually, the Area Under the Curve with respect to increase (AUCi) was calculated as a single measure of the total hormone (i.e., cortisol) concentration in response to the MAST or control task (Pruessner et al., 2003). The following formula was used to compute the AUCi: $\left(\left(\left(\left(t_{+0}+t_{\text {pre-stress }}\right) / 2\right) * 15\right)+\left(\left(\left(t_{+20}+t_{+0}\right) / 2\right) * 20\right)+\right.$ $\left(\left(\left(t_{+40}+t_{+20} / 2\right) * 20\right)+\left(\left(\left(t_{+50}+t_{+40}\right) / 2\right) * 15\right)\right)-\left(t_{\text {pre-stress }}\right.$ * $(15+20+20+15))$. The effect of timing of stress exposure on memory performance (free recall \%, hits, $F A, P r$ and $B r$ ) and the LPP during encoding taking into account the different stimulus types was assessed using 2 (Picture Type: neutral, negative) $\times 2$ (Condition: stress vs. control) $\times 2$ (Timing: proximate vs. distant) ANOVA with Picture Type as withinsubject factor. To explore possible relationships between participants' physiological stress response and memory, bivariate Pearsons's correlations were conducted. We used a hypothesis driven approach for the correlations to limit the inflation of Type I error rates in these analyses. We used Greenhouse-Geisser correction when the assumption of sphericity in the repeated measures ANOVA was not met. All post hoc comparisons were performed using Bonferroni correction for multiple comparisons. In case of significant results, ANOVAs are supplemented with Partial Eta Squared $\left(\eta_{\mathrm{p}}^{2}\right)$ values as a measure of effect size $\left(\eta_{\mathrm{p}}^{2}\right.$ of .01 indicate small effects, $\eta_{\mathrm{p}}^{2}$ of .06 medium effects, and $\eta_{\mathrm{p}}^{2}$ of .14 large effects; Fritz et al., 2012).

\section{Results}

\subsection{Subjective and neuroendocrine stress responses}

For PANAS Negative Affect, a significant Measurement $\times$ Stress interaction $\left(F_{(1,59)}=20.38, p<.001, \eta_{\mathrm{p}}^{2}=.26\right)$ was 


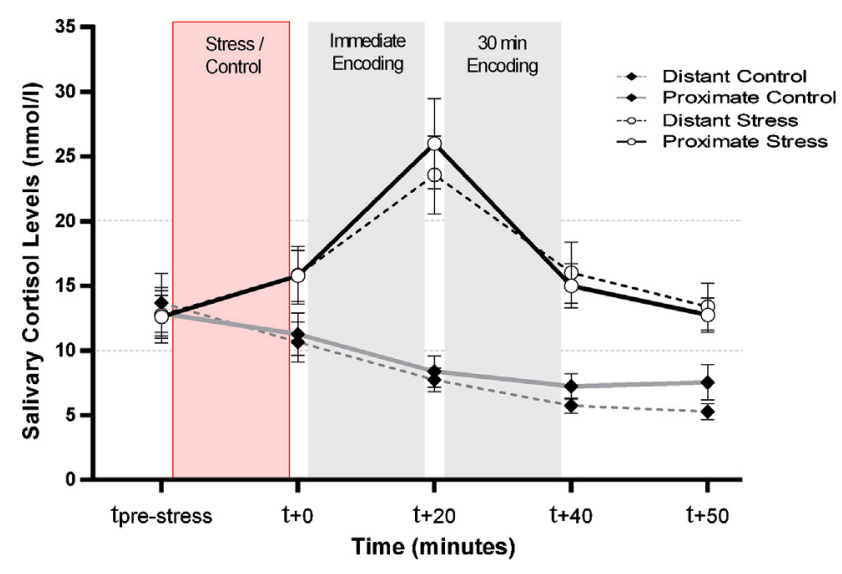

Figure 2 Salivary cortisol responses to the Maastricht Acute Stress Test (MAST). Graphs show means $\pm \mathrm{SE}$.

found. Follow-up tests indicate that both stress groups showed an increase in negative affect in response to the stressor. Mean PANAS change after stress minus before stress (Most-Pre) were $5.5(S E M=1.79)$ in the proximate stress group $\left(t_{(15)}=3.08, p=.008\right)$, and $2.7(S E M=0.90)$ in the distant stress group $\left(t_{(15)}=2.98, p=.009\right)$. Both control conditions did not show an increase (proximate control: $t_{(15)}=-2.12, \quad p=.051, \quad M_{\text {Post-Pre }}=-0.94, \quad S E M=0.44$, distant control: $t_{(14)}=-1.07, p>.30, M_{\text {Post-Pre }}=-0.47$, SEM $=0.43$ ).

Mean salivary cortisol concentrations prior to and following the (no-stress control) MAST are shown in Fig. 2. For the salivary cortisol concentrations, a significant Measurement $\times$ Stress interaction $\left(F_{(4,236)}=50.14, p<.001 ; \eta_{\mathrm{p}}^{2}=\right.$ $.46 ; \varepsilon=.39$ ) was found. Simple effects per saliva time point revealed higher cortisol concentrations in the stress groups compared to the control groups at $t_{+0}\left(F_{(1,60)}=6.73\right.$, $\left.p=.012 ; \quad \eta_{\mathrm{p}}^{2}=.10\right), \quad t_{+20} \quad\left(F_{(1,60)}=47.32, \quad p<.001 ;\right.$ $\left.\eta_{\mathrm{p}}^{2}=.44\right), \quad t_{+40} \quad\left(F_{(1,60)}=32.33, \quad p<.001 ; \quad \eta_{\mathrm{p}}^{2}=.35\right) \quad$ and $t_{+50 \min }\left(F_{(1,60)}=23.47, p<.001 ; \eta_{\mathrm{p}}^{2}=.28\right)$ but not at $t_{\text {pre-stress }}$ $\left(F_{(1,60)}=0.10 ; p=.76\right)$. Moreover, a univariate ANOVA indicated that the cortisol baseline during the recall task on day 2 did not differ between the four groups (Stress: $F_{(1,60)}=1.05, p=.31$; Measurement: $\left.F_{(1,60)}=0.04, p=.95\right)$. None of the other interaction and main effects was significant.

\subsection{Behavioral results}

Mean scores derived from the free recall and recognition test are shown in Table 1. Free recall performance was affected by the emotional content of the pictures, as demonstrated by a significant main effect of Picture Type $\left(F_{(1,58)}=60.26\right.$, $\left.p<.001 ; \eta_{p}^{2}=.51\right)$, with negative pictures being remembered better. Stress and Timing did not differentially affect the recall per picture type, as indicated by the non-significant Picture Type $\times$ Stress $\times$ Timing interaction $\left(F_{(1,58)}=\right.$ $0.26, p=.61$ ) and the finding that none of the other interactions were significant. There was however a significant main effect of Stress $\left(F_{(1,58)}=6.88, p=.01 ; \eta_{\mathrm{p}}^{2}=.11\right)$, with stress decreasing the number of pictures that were correctly remembered. Within the stress groups, Pearson's correlations between the percentage correct free recall of negative and neutral pictures on the one hand and the stress-induced changes in cortisol (AUCi) on the other hand were performed to evaluate the relationship between participants' physiological stress responses and long-term memory performance. All correlations were non-significant ( $p$ 's $>.16$ ).

The analysis of the recognition data defined by the percentage hits (correct detection of old pictures) did not reveal any interaction or main effects involving Picture Type, Stress or Timing (all $p$ 's $>$.13). Yet, the analysis of false alarms revealed a main effect of Stress $\left(F_{(1,58)}=7.35, p=.009\right.$;

Table 1 Means $( \pm \mathrm{SE})$ of Long-term (24-h) memory for negative and neutral pictures displayed as percentage free recall, percentage hits, false alarms, corrected recognition $(\mathrm{Pr})$ and bias index $(\mathrm{Br})$.

\begin{tabular}{|c|c|c|c|c|}
\hline & Proximate stress & Distant stress & Proximate control & Distant contro \\
\hline \multicolumn{5}{|c|}{ Free recall (\%) } \\
\hline Neutral & 10.19 (1.07) & $11.81(1.35)$ & $13.37(1.48)$ & $14.26(1.86)$ \\
\hline Negative & 18.52 (1.79) & $20.14(1.78)$ & $23.61(1.81)$ & $22.22(1.94)$ \\
\hline \multicolumn{5}{|c|}{ Recognition (hits\%) } \\
\hline Neutral & $95.83(0.98)$ & 95.31 (1.26) & $95.31(1.54)$ & $96.48(1.16)$ \\
\hline Negative & $94.97(1.30)$ & $94.44(1.43)$ & $94.44(1.39)$ & 95.37 (1.29) \\
\hline \multicolumn{5}{|c|}{ False alarms (FA\%) } \\
\hline Neutral & 9.72 (2.85) & $9.72(2.98)$ & $4.86(1.89)$ & $6.30(2.48)$ \\
\hline Negative & $16.67(2.87)$ & $19.10(3.29)$ & 9.03 (1.96) & $10.37(2.23)$ \\
\hline \multicolumn{5}{|c|}{ Recognition $(P r)$} \\
\hline Neutral & $0.91(0.02)$ & $0.90(0.02)$ & $0.93(0.02)$ & $0.93(0.02)$ \\
\hline Negative & $0.87(0.02)$ & $0.85(0.03)$ & $0.90(0.02)$ & $0.90(0.02)$ \\
\hline \multicolumn{5}{|c|}{ Bias index $(B r)$} \\
\hline Neutral & $0.49(0.06)$ & $0.50(0.06)$ & $0.40(0.05)$ & $0.48(0.06)$ \\
\hline Negative & $0.58(0.06)$ & $0.62(0.05)$ & $0.50(0.04)$ & $0.53(0.05)$ \\
\hline
\end{tabular}

Note: For free recall, corrected recognition $(P r)$, and false alarms $(F A \%)$, a significant main effect of stress was found $(p=.01, p=.04$, $p=.009$ respectively). A significant main effect of picture type was found for free recall, corrected recognition $(\mathrm{Pr})$, bias index $(\mathrm{Br})$, and false alarms (all $p$ 's $<.001$ ). 


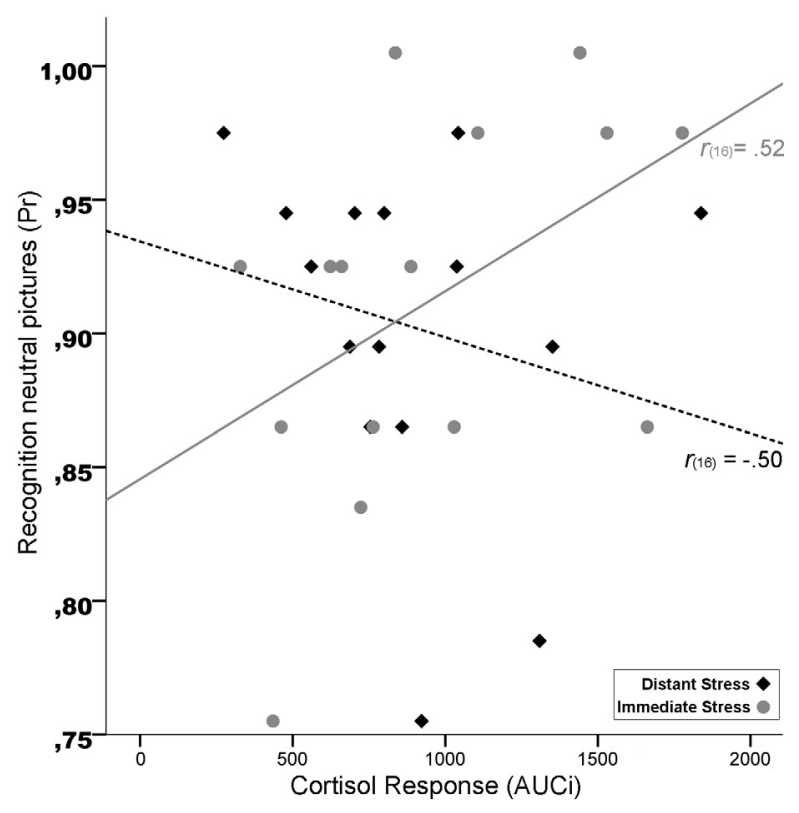

Figure 3 Correlations between the cortisol response (AUCi) and the recognition performance (Pr) of neutral pictures. Stressinduced cortisol changes are reversely associated with subsequent recognition of neutral pictures in the proximate and distant stress groups. Note that the two correlations significantly differ from each other $(p<.001)$.

$\left.\eta_{\mathrm{p}}^{2}=.11\right)$, with stress increasing the number of false alarms, as well as a main effect of Picture Type $\left(F_{(1,58)}=20.45\right.$, $p<.001 ; \eta_{\mathrm{p}}^{2}=.26$ ), with negative pictures producing higher false alarm rates (no significant interactions emerged; all $p$ 's $>$.15). Moreover, the number of false alarms of neutral pictures was negatively related to the stress-induced changes in cortisol (AUCi) in the proximate condition $\left(r_{(15)}=-.53\right.$, $p=.04)$.

The analysis of the discrimination index $\mathrm{Pr}$ revealed that recognition performance was affected by the emotional content of the pictures, as demonstrated by a significant main effect of Picture Type $\left(F_{(1,58)}=16.90, p<.001\right.$; $\eta_{\mathrm{p}}^{2}=.22$ ), with neutral pictures being better discriminated. Stress and Timing did not differentially affect recall per picture type, as indicated by the non-significant Picture Type $\times$ Stress $\times$ Timing interaction $\left(F_{(1,58)}=0.06, p=.80\right)$, and none of the other interactions were significant. There was however a significant main effect of Stress $\left(F_{(1,58)}=4.24\right.$, $\left.p=.04 ; \eta_{\mathrm{p}}^{2}=.07\right)$, with stress decreasing the discrimination of old/new pictures. ${ }^{1}$ Moreover, the correct recognition of neutral pictures correlated with the stress-induced changes in cortisol (AUCi). Specifically, in the Proximate stress group, a positive correlation $\left(r_{(15)}=.52, p=.05\right)$ between AUCi and the number of correct recognized neutral pictures was found. While in the distant stress group, a negative correlation

\footnotetext{
${ }^{1}$ The recognition task consisted of $25 \%$ new similar and $25 \%$ new different pictures. The analysis of the recognition memory (Pr) separately for new similar and new different items yielded highly similar results as the analysis of the overall $\mathrm{Pr}$, with stress decreasing the number of recognized pictures, independent of the picture type or the timing of the stressor.
}

$\left(r_{(16)}=-.50, p=.05\right)$ between AUCi and the number of correct recognized neutral pictures was found (see Fig. 3). These correlations with the cortisol response (AUCi) are significantly different $(Z=2.85, p<.001)$. Importantly, these effects were obtained without group differences in $\mathrm{Br}$ (all p's $>$.14). ${ }^{2}$

\subsection{ERP results: late positive potential}

The overall shape of encoding ERPs was similar for neutral and negative pictures (see Figs. 4 and 5). As expected, mean LPP amplitudes for negative pictures were more positive going than for neutral pictures (Neutral $M=6.25$, $S E M=0.52$; Negative $M=8.59$, SEM $=0.68 ; F_{(1,56)}=26.24$, $p<.001 ; \eta_{\mathrm{p}}^{2}=.32$ ). Stress and Timing did not differentially affect the LPP in the 500-1000 ms window per picture type, as indicated by the non-significant interaction and main effects (Stress $\times$ Timing $\times$ Picture Type interaction $F_{(1,56)}=$ $1.22, p=.28)$. Within the stress groups, Pearson's correlations between the amplitude of the LPP in the $500-1000 \mathrm{~ms}$ window of negative and neutral pictures on the one hand and stress-induced changes in cortisol (AUCi) on the other hand were performed to evaluate the relationship between participants' physiological stress responses and information processing. In the proximate stress group, AUCi correlated positively with the amplitude of the LPP for negative pictures $\left(r_{(14)}=.54, p=.05\right)$, while in the distant stress group a negative correlation $\left(r_{(16)}=-.51, p=.05\right)$ between AUCi and the amplitude of the LLP for neutral pictures was found.

Based on visual inspection, the effect of Stress and Timing on the late LPP was also analyzed. The late LPP was scored by mean activity in successive 500 ms windows from 1 to $2.5 \mathrm{~s}$. The ANOVAs of the LPP in the 1000-1500 ms, 1500-2000 ms and 2000-2500 ms window all indicated a main effect of Picture Type, with negative pictures eliciting a larger (more positive) LPP irrespective of Stress or Timing $\left(F_{(1,56)}=8.59\right.$, $p<.005 ; \quad \eta_{\mathrm{p}}^{2}=.13 ; \quad F_{(1,56)}=12.00, \quad p=.001 ; \quad \eta_{\mathrm{p}}^{2}=.18 ;$ $F_{(1,56)}=3.03, p=.09 ; \eta_{\mathrm{p}}^{2}=.05$, respectively). Separate ANOVAs per picture type for the LPP in the 1500-2000 ms window revealed a main effect of Stress at trend level for neutral pictures $\left(F_{(1,56)}=3.42, p=.07 ; \eta_{p}^{2}=.06\right)$ with stress decreasing (less positive) the LPP in the 1500-2000 ms time window. No interaction or main effects were significant for negative pictures or for the LPP in the 1000-1500 and 2000-2500 ms window. ${ }^{3}$

\subsubsection{Exploratory analysis of early ERPs}

A data driven approach was chosen to evaluate the effects of stress on early ERP components. Visual inspection served to determine areas of interest, which are shown in Figs. 6 and 7.

\footnotetext{
${ }^{2}$ In the current sample, 7 non-responders (i.e. participants who did not show a cortisol elevation $>2.5 \mathrm{mmol} / \mathrm{l}$ to the MAST) were identified. When the analyses were restricted to data from only cortisol responders, the $2 \times 2 \times 2$ ANOVAs yielded highly similar results.

${ }^{3}$ When the exploratory ERP analyses were restricted to data from only cortisol responders, the $2 \times 2 \times 2$ ANOVAs yielded highly similar results. Except for the LPP in the 1500-2000 ms time window, the main effect of stress for neutral pictures became significant $\left(F_{(1,49)}=4.63 ; p=.04 ; \eta_{\mathrm{p}}^{2}=.09\right)$, with stress decreasing (less positive) the LPP in the $1500-2000 \mathrm{~ms}$ window.
} 


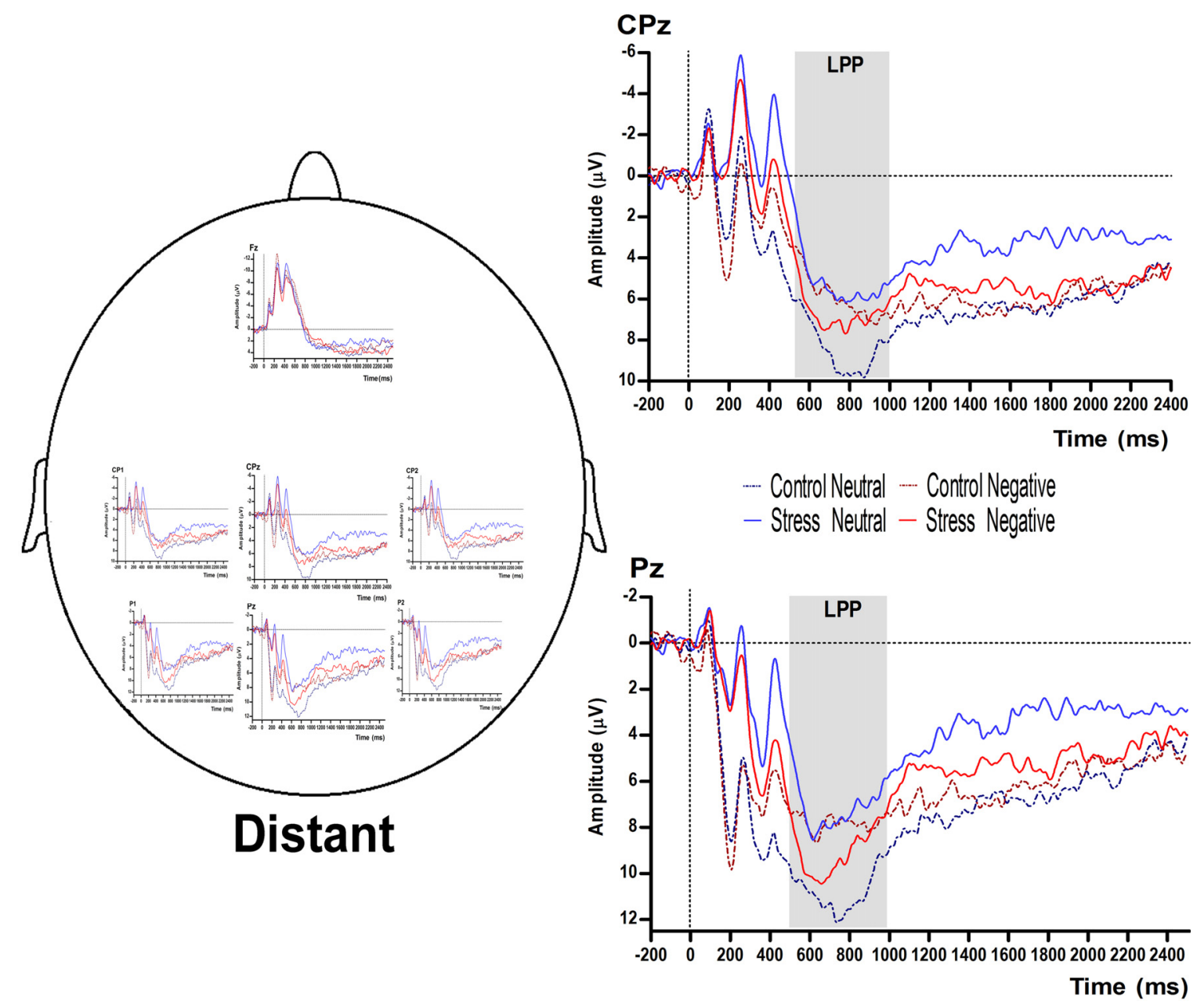

Figure 4 Grand-averaged ERP waveforms over two scalp electrodes (CPz and Pz) for all neutral (blue line) and negative (red line) pictures for the distant condition (control dotted line; stress solid line). The LPP was determined as the mean ERP amplitude in the window of 500-1000 ms, 1000-1500 ms, 1500-2000 ms and 2000-2500 ms over a cluster of centro-parietal electrodes (CP1, CPz, CP2, $\mathrm{P} 1, \mathrm{Pz}, \mathrm{P} 2)$. The LPP was larger for negative pictures compared to positive pictures $(p<.001)$. For the LPP in the $1500-2000 \mathrm{~ms}$ window a main effect of stress was found with stress decreasing the LPP for neutral pictures $(p=.05)$. (For interpretation of the references to color in this figure legend, the reader is referred to the web version of the article.)

The $\mathrm{N} 100$ was measured as the mean amplitude in the window of 75-125 ms at Fz, the P200 in the window of $150-220 \mathrm{~ms}$ at $\mathrm{Pz}$, and the N200 was in the window of 220-300 ms at CPz.

For the N100, a significant Stress $\times$ Timing $\times$ Picture Type interaction $\left(F_{(1,56)}=6.63, p=.01 ; \eta_{\mathrm{p}}^{2}=.11\right)$ was found. Follow-up analysis per Picture Type revealed for negative pictures a Stress $\times$ Timing interaction at trend level $\left(F_{(1,56)}=2.85, p=.10 ; \eta_{\mathrm{p}}^{2}=.05\right)$, but no interaction or main effects for neutral pictures ( $p$ 's $>.38$ ). However, post hoc analyses for negative pictures revealed that the stress effect was not significant in any of the separate ANOVAs per timing.

For the P200, a Stress $\times$ Timing $\times$ Picture Type interaction at trend level was found $\left(F_{(1,56)}=3.75, p=.06 ; \eta_{p}^{2}=.06\right)$. The corresponding two-way interactions for each picture type were significant (negative pictures: Stress $\times$ Timing $F_{(1,56)}=5.70, \quad p=.02 ; \quad \eta_{p}^{2}=.09 ; \quad$ neutral pictures: Stress $\times$ Timing $\left.F_{(1,56)}=13.32, \quad p<.001 ; \eta_{\mathrm{p}}^{2}=.19\right)$. Post hoc analyses per timing revealed that for both negative and neutral pictures, stress $30 \mathrm{~min}$ before encoding decreased (less positive) the P200 compared to the control group (negative pictures: $F_{(1,28)}=9.83, p<.005 ; \eta_{\mathrm{p}}^{2}=.26$; neutral pictures: $\left.F_{(1,28)}=19.15, p<.001 ; \eta_{\mathrm{p}}^{2}=.41\right)$, whereas the effect of stress was not significant for the proximate condition in any of the separate ANOVAs per picture type ( $p$ 's $>.40)$.

For the N200, a significant Stress $\times$ Timing $\times$ Picture Type interaction $\left(F_{(1,56)}=7.15, p=.01 ; \eta_{\mathrm{p}}^{2}=.11\right)$ was found. Follow-up analyses per Picture Type revealed for neutral pictures a Stress $\times$ Timing interaction at trend level $\left(F_{(1,56)}=2.85, p=.10 ; \eta_{\mathrm{p}}^{2}=.05\right)$, but no interaction or main effects for negative pictures (all $p$ 's $>.12$ ). For neutral pictures, simple effects per timing suggest that stress 30 min before encoding increased the $\mathrm{N} 200$ (more negative) compared to the control group $\left(F_{(1,28)}=6.29, p=.02\right.$; $\left.\eta_{\mathrm{p}}^{2}=.18\right)$, whereas this stress effect remained non-significant in the proximate stress group.

\section{Discussion}

The primary aim of the current study was to investigate the influence of stress applied immediately or 30 min prior to encoding on information processing and on long-term (24 h) 


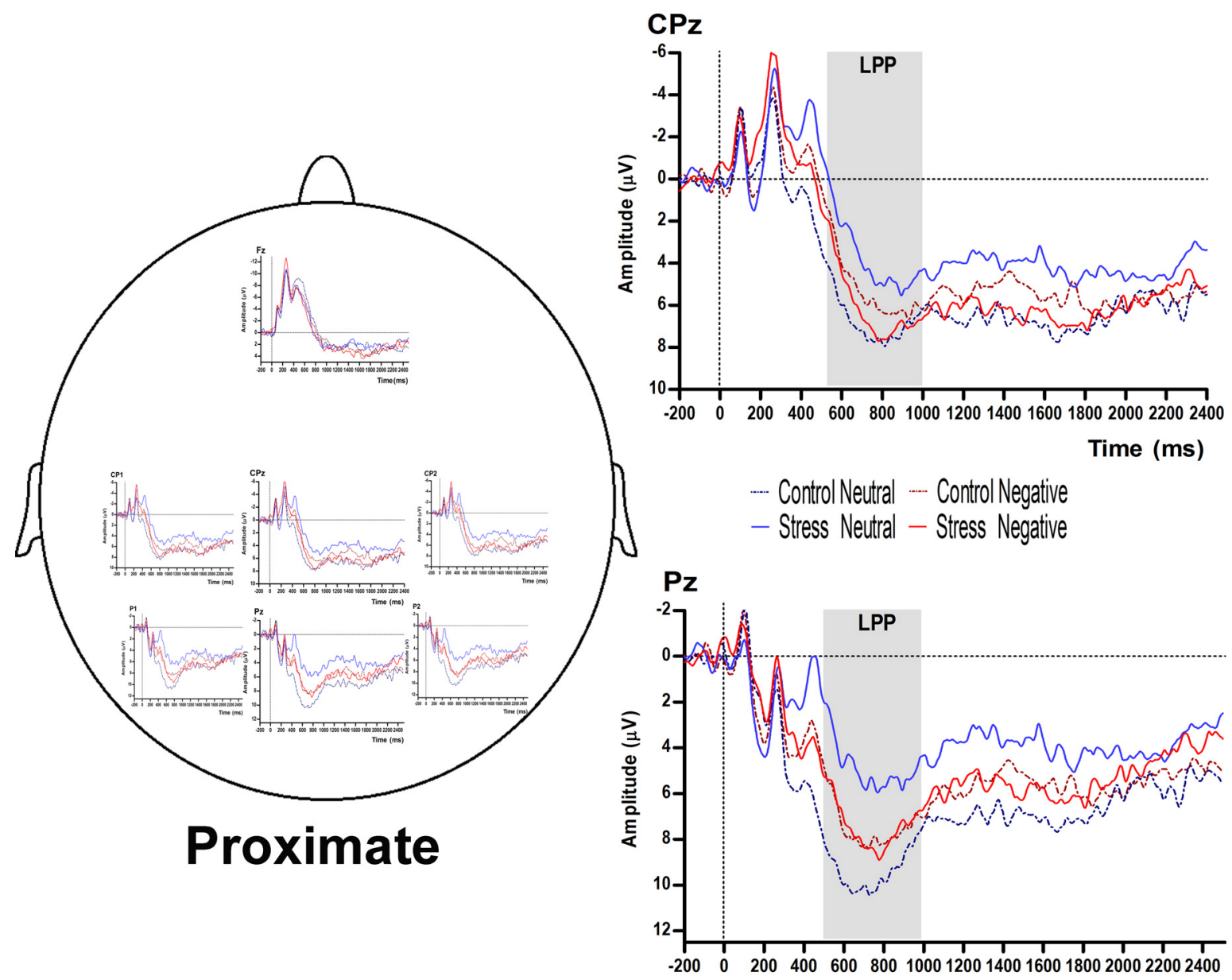

Time (ms)

Figure 5 Grand-averaged ERP waveforms over two scalp electrodes (CPz and Pz) for all neutral (blue lines) and negative pictures (red lines) for the proximate condition (control dotted line; stress solid line). The LPP was determined as the mean ERP amplitude in the window of $500-1000 \mathrm{~ms}, 1000-1500 \mathrm{~ms}, 1500-2000 \mathrm{~ms}$ and 2000-2500 ms over a cluster of centro-parietal electrodes (CP1, CPz, CP2, $\mathrm{P} 1, \mathrm{Pz}, \mathrm{P2})$. The LPP was larger for negative pictures compared to positive pictures $(p<.001)$. For the LPP in the 1500-2000 ms window a main effect of stress was found with stress decreasing the LPP for neutral pictures $(p=.05)$. (For interpretation of the references to color in this figure legend, the reader is referred to the web version of the article.)

memory performance. Results demonstrate that participants in both stress groups displayed significant stress responses in terms of subjective negative affect scores and cortisol levels compared to the no-stress control conditions. In general, stress decreased the number of freely recalled and recognized pictures, increased the number of false alarms and decreased the LPP in the 1500-2000 ms window of neutral pictures. Moreover, stress-induced cortisol responses (AUCi) and correctly recognized neutral pictures were positively associated within the proximate stress group, whereas they were negatively associated within the distant stress group.

The present finding of stress increasing the number of false alarms is in line with previous research suggesting specific memory alternations due to stress-induced cortisol levels (Domes et al., 2004). This increase in false alarms was not produced by an effect of stress on the general probability of answering yes as indicated by the non-significant effect of stress on the response bias. This latter finding to some extent disagrees with previous work showing a more liberal response bias for neutral information as a consequence of a stress-induced hypervigilant neural state resulting in more generalized memory encoding (Qin et al., 2012). Nevertheless, timing of the stressor did not differentially affect the number of false alarms. Moreover, in contrast to Zoladz et al. (2011), a differential effect of proximate versus distant stress on subsequent memory performance was not found although we did find opposite correlations between the stress-induced cortisol response and the correct recognition of neutral pictures in the two stress timing groups. Zoladz et al. (2011) found an enhancing effect of stress applied immediately prior to learning for positive words on recognition memory and an impairing effect of stress applied $30 \mathrm{~min}$ prior to learning for negative words on free recall in cortisol responders. In the same vein, we found that stress-induced cortisol responses and correctly recognized neutral pictures were positively associated within the proximate stress group, but negatively within the distant stress group. Another apparent difference with Zoladz et al. (2011) is that we found associations with cortisol responses only for correct recognition of neutral pictures but not for the emotional 


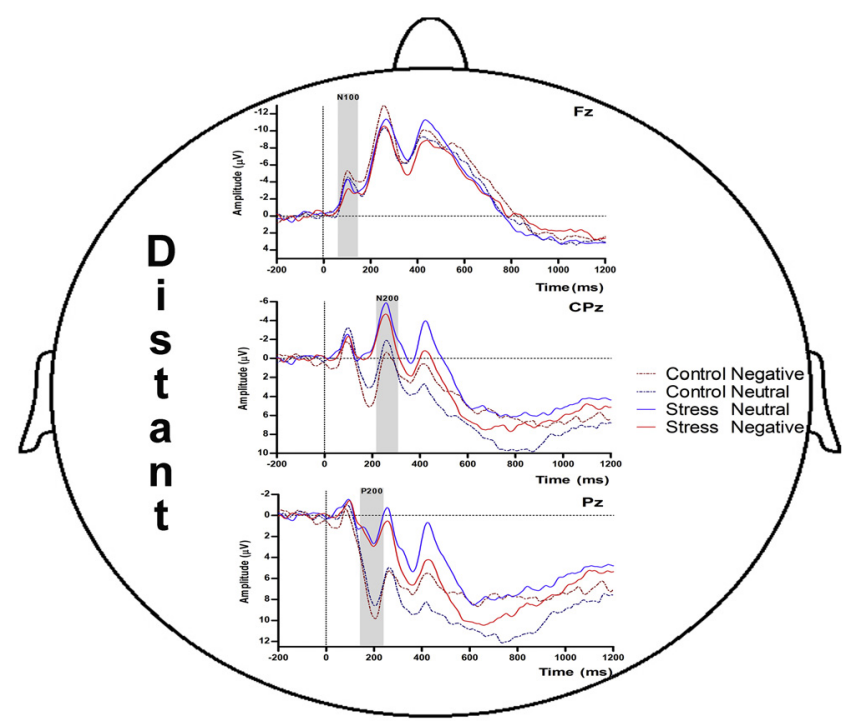

Figure 6 Grand-averaged waveforms depicting early ERP components for all neutral (blue lines) and negative (red lines) pictures for the distant condition (control dotted lines; stress solid lines). Notre that the P200 (150-220 ms) for negative and neutral pictures was decreased by stress $30 \mathrm{~min}$ before encoding (both $p$ 's $<.01)$. The N200 (220-300 ms) for neutral pictures was increased by stress 30 min before encoding $(p=.02)$. (For interpretation of the references to color in this figure legend, the reader is referred to the web version of the article.)

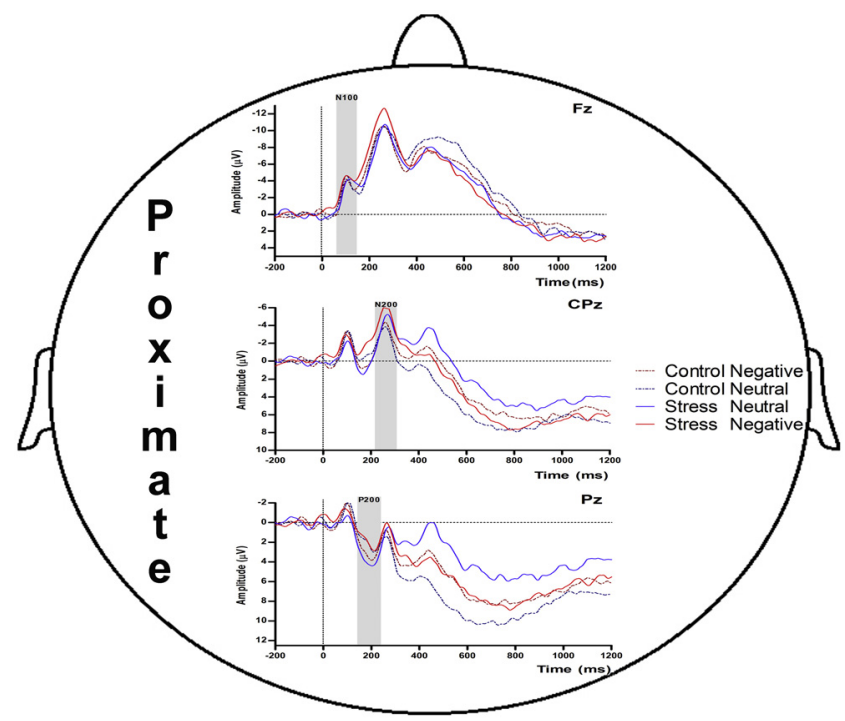

Figure 7 Grand-averaged waveforms depicting early ERP components for all neutral (blue lines) and negative (red lines) pictures for the proximate condition (control dotted lines; stress solid lines). (For interpretation of the references to color in this figure legend, the reader is referred to the web version of the article.)

pictures. Methodological differences can at least in part explain these divergent findings. For example, while Zoladz et al. (2011) used a word list paradigm, the current study employed a pictorial task that lasted $18 \mathrm{~min}$. Additionally, while being comparable in size, the study sample in Zoladz et al. (2011) was predominantly female while the current study only consisted of men. This could be important given that memory performance of men could be more affected by stress-induced cortisol elevations than that of women (e.g., Wolf et al., 2001).

We found that stress decreased the amount of recalled and correctly recognized neutral and negative pictures. Overall, studies that have investigated the effect of stress on memory encoding have yielded divergent findings, with some reporting enhanced subsequent memory performance (e.g., Kuhlmann and Wolf, 2006; Nater et al., 2007; Schwabe et al., 2008; Smeets et al., 2009), others finding no effect (e.g., de Quervain et al., 2000; Domes et al., 2002; Smeets et al., 2008), impairing effects (e.g., Kirschbaum et al., 1996; Lupien et al., 1997; Kim et al., 2001), and still others reporting emotion dependent effects. For example, studies similar in design to the current study investigating preencoding stress in an incidental learning paradigm on delayed recall revealed an impairment of neutral information while emotional information was enhanced (Payne et al., 2006, 2007). It has been proposed that emotionally distressing situations might introduce a longer time window during which encoding of emotional information is not impaired (Smeets et al., 2009; Karst et al., 2010) which might be mediated by GC activation of the amygdala. Note that we did not obtain a generally better recognition performance for negative pictures than neutral pictures, while this emotional memory enhancement effect was observed for the free recall data. These results might appear to be conflicting and at odds with prior studies reporting an emotion memory enhancement effect. Yet, there are also examples of studies that did not find this emotional enhancement effect (e.g., Schwabe and Wolf, 2010; Zoladz et al., 2011, 2013). This effect may not have taken place in the present study because in general, the percentage correctly recognized old pictures was near ceiling irrespective of condition (i.e., $M_{\mathrm{Hit}}>94 \%$ ) which can have obscured emotion effects on recognition memory.

The exploratory ERP analyses revealed that stress $30 \mathrm{~min}$ before encoding decreased the P200 for negative and neutral pictures while it increased the N200 for neutral pictures. It has been proposed that the amplitude of those two mid latency components reflect automatic post-perceptual selective attention (Luck, 2005). A reduced P200 amplitude and an increased N200 amplitude has also been found in post-traumatic stress patients (PTSD) and in anxiety disorders in general (e.g., Felmingham et al., 2002; Wessa et al., 2005; Sass et al., 2010; see for a review in PTSD: Javanbakht et al., 2011) reflecting the distorted attentional bias and hyperarousal symptoms found in anxiety related disorders. The observation of an early modulation of the ERP by stress 30 min before encoding support the idea of sensory hyperarousal under stress affecting attention-modulated information processing.

In line with previous research, the amplitude of the LPP in the $500-1000 \mathrm{~ms}$ window was larger for negative than for neutral pictures, known as the emotion effect (e.g., Dolcos and Cabeza, 2002). Stress decreased the LPP in the 15002000 ms window for neutral pictures although irrespective of the timing of the stressor. Markedly, stress-induced cortisol responses (AUCi) were negatively associated with the amplitude of the LPP in the 500-1000 ms window within the distant stress group. Interestingly, the correct recognition of neutral pictures also correlated negatively with the AUCi in this distant 
stress group. It seems that stress 30 min before encoding decreased attentional allocation to neutral information thereby impairing the processing of new information. This observed antagonistic link on the behavioral and information processing level between the increase in cortisol and neutral information may mirror a refractory state of the hippocampus induced by genomic GR as well as non-genomic MR actions (Joëls et al., 2006; Diamond et al., 2007; Karst et al., 2010; Joëls et al., 2011). It is known that acute stress results in the release of neurotransmitters like noradrenaline in amongst others the prefrontal cortex (e.g., Arnsten, 2009). Based on animal and human work, it has been proposed that an interaction of GCs with the noradrenergic system in the BLA is crucial for stress to affect emotional memory (e.g. Roozendaal et al., 2009; Roozendaal and McGaugh, 2011). In line with this suggestion, we found a positive association between the AUCi and the amplitude of the LPP in the 500-1000 ms window for negative pictures within the proximate stress group. Our finding is also in accordance with Weymar et al. (2012) who found a selective enhancement of the LPP for unpleasant pictures in stressed participants suggesting that pre-learning stress tunes the brain for the processing of biologically relevant stimuli. Nevertheless, the present study did not replicate the finding of Weymar et al. (2012) regarding a positive correlation between the amplitude of the LPP of unpleasant pictures and memory performance $24 \mathrm{~h}$ later among stressed participants.

The fact that the timing of pre-learning stress did not directly affect attentional processing (i.e., LPP amplitude) or long term memory could indicate the need for a finer delineation of the precise time windows during which stress and glucocorticoids can affect memory encoding processes. For example, Diamond et al. (2007) found that predator stress immediately but not $30 \mathrm{~min}$ prior to learning in the water maze enhanced long-term memory in rats. Unfortunately, the task measurements used by Diamond et al. (2007) did not allow assessing the model based anticipated memory impairments when stress was applied 30 min before learning. Although animal research has been very valuable regarding the time dependent involvement of the MR and GR receptors to stress responses (e.g., de Kloet, 2008), translation to humans seems to be intricate (e.g., Smeets et al., 2009; Zoladz et al., 2011).

Some limitations to the current study are worth mentioning. First, we did not measure activity of the sympathetic nervous system (e.g., via salivary alpha-amylase). However, it is very likely that by using emotionally arousing IAPS pictures, the current task also stimulated the adrenergic system including the amygdala (e.g., Phan et al., 2002; van Stegeren et al., 2010). In support of this interpretation, the used negative IAPS pictures were subjectively rated as arousing. Second, several studies involving acute psychological stressors have occasionally found evidence suggesting that sex differences may modulate the effects of GCs on memory. Future studies using the current study design may benefit from including both males and females. Third, it would be interesting to investigate the effect of stress before encoding on the electrophysiological signature of remembered items, i.e., the subsequent memory effect (e.g., Dolcos and Cabeza, 2002). This was not possible in the current study since 36 pictures per category were presented and the mean free recall percentage was $15 \%$, which clearly is an insufficient number of trials for ERP averaging. Future studies should take the low percentage of free recall into account, for instance by including more pictures in the encoding task. Moreover, the current study included moderately arousing unpleasant pictures. Effects of picture arousal on the LPP have consistently been found (see for a review Olofsson et al., 2008) indicating the need to examine the effect of the proximity of stress on the encoding of high arousing stimuli. Finally, we have interpreted some of the findings based on high correlations found in relatively small samples. In order to further delineate the effect of timing of stress on memory, future work with larger sample sizes will need to be conducted.

In sum, the results of this study suggest that the time at which a stressor is applied might differentially impact the association between stress-induced cortisol elevations and memory formation for emotionally arousing and neutral events learned after the stressor. Thereby, this study adds knowledge to the relatively sparse and inconsistent literature regarding the modulating effects of stress on memory formation. Administering stress prior to encoding seems a promising avenue to extend the temporal dynamics model of emotional memory processing (Joëls et al., 2006; Diamond et al., 2007) that is supported by numerous studies demonstrating enhancing effects when stress is applied after learning during memory consolidation while stress applied before retrieval impairs memory. Thus, future studies should further delineate the exact time window under which memory is enhanced or impaired by acute psychosocial stress separately across different types of memory (e.g., emotional and neutral) and different memory paradigms (e.g., words, pictorial, incidental, and intentional), while carefully controlling for time of day and gender. Meanwhile, imaging techniques like EEG should be used since they seem to be more sensitive and can help to determine the underlying neurobiological mechanism.

\section{Role of the funding sources}

This research was supported by grant 056-25-011 from the Netherlands Organization for Scientific Research (NWO) to Dr. Tom Smeets. NWO had no further role in the study design; in the collection, analysis and interpretation of the data; in the writing of the report; and in the decision to submit the paper for publication.

\section{Conflict of interest}

No conflicts of interest are declared.

\section{Acknowledgments}

We are especially thankful to Loran van der Hoeven, Sophie Lijdsman and Celine Savelkoul for the help in collecting the data.

\section{Appendix A. Supplementary data}

Supplementary data associated with this article can be found, in the online version, at http://dx.doi.org/10.1016/ j.psyneuen.2013.09.002. 


\section{References}

Arnsten, A.F., 2009. Stress signalling pathways that impair prefrontal cortex structure and function. Nat. Rev. Neurosci. 10, 410-422.

Cahill, L., Gorski, L., Le, K., 2003. Enhanced human memory consolidation with post-learning stress: interaction with the degree of arousal at encoding. Learn. Mem. 10, 270-274.

Cuthbert, B.N., Schupp, H.T., Bradley, M.M., Birbaumer, N., Lang, P.J., 2000. Brain potentials in affective picture processing: covariation with autonomic arousal and affective report. Biol. Psychol. 52, 95-111.

de Kloet, E.R., 2008. About stress hormones and resilience to psychopathology. J. Neuroendocrinol. 20, 885-892.

de Kloet, E.R., Joëls, M., Holsboer, F., 2005. Stress and the brain: from adaptation to disease. Nat. Rev. Neurosci. 6, 463-475.

de Quervain, D.J., Roozendaal, B., McGaugh, J.L., 1998. Stress and glucocorticoids impair retrieval of long-term spatial memory. Nature 394, 787-790.

de Quervain, D.J., Roozendaal, B., Nitsch, R.M., McGaugh, J.L., Hock, C., 2000. Acute cortisone administration impairs retrieval of long-term declarative memory in humans. Nat. Neurosci. 3, 313-314.

Diamond, D.M., Campbell, A.M., Park, C.R., Halonen, J., Zoladz, P.R., 2007. The temporal dynamics model of emotional memory processing: a synthesis on the neurobiological basis of stressinduced amnesia, flashbulb and traumatic memories, and the Yerkes-Dodson law. Neural Plast. 2007, 60803.

Dolcos, F., Cabeza, R., 2002. Event-related potentials of emotional memory: encoding pleasant, unpleasant, and neutral pictures. Cogn. Affect. Behav. Neurosci. 2, 252-263.

Domes, G., Heinrichs, A., Reichwald, U., Hautzinger, M., 2002. Hypothalamic-pituitary-adrenal axis reactivity to psychological stress and memory in middle-aged women: high responders exhibit enhanced declarative memory performance. Psychoneuroendocrinology 27, 843-853.

Domes, G., Heinrichs, M., Rimmele, U., Reichwald, U., Hautzinger, M., 2004. Acute stress impairs recognition for positive words association with stress-induced cortisol secretion. Stress 7, 173181.

Felmingham, K.L., Bryant, R.A., Kendall, C., Gordon, E., 2002. Event-related potential dysfunction in posttraumatic stress disorder: the role of numbing. Psychiat. Res. 109, 171-179.

Fritz, C.O., Morris, P.E., Richler, J.J., 2012. Effect size estimates: current use, calculations, and interpretation. J. Exp. Psychol. Gen. 141, 2-18.

Hajcak, G., Weinberg, A., MacNamara, A., Foti, D., 2012. ERPs and the study of emotion. In: S. J. Luck, S.J., Kappenman, E.S. (Eds.), The Oxford Handbook of Event-related Potential Components. Oxford University Press Inc., New York, pp. 441-474.

Javanbakht, A., Liberzon, I., Amirsadri, A., Gjini, K., Boutros, N.N., 2011. Event-related potential studies of post-traumatic stress disorder: a critical review and synthesis. Biol. Mood Anxiety Disord. 1, 5.

Joëls, M., Fernandez, G., Roozendaal, B., 2011. Stress and emotional memory: a matter of timing. Trends Cogn. Sci. 15, 280-288.

Joëls, M., Karst, H., DeRijk, R., de Kloet, E.R., 2008. The coming out of the brain mineralocorticoid receptor. Trends Neurosci. 31, 17.

Joëls, M., Pu, Z., Wiegert, O., Oitzl, M.S., Krugers, H.J., 2006. Learning under stress: how does it work? Trends Cogn. Sci. 10, 152-158.

Karst, H., Berger, S., Erdmann, G., Schutz, G., Joëls, M., 2010. Metaplasticity of amygdalar responses to the stress hormone corticosterone. Proc. Natl. Acad. Sci. U.S.A. 107, 1444914454.

Kim, J.J., Lee, H.J.J., Han, J.S., Packard, M.G., 2001. Amygdala is critical for stress-induced modulation of hippocampal long-term potentiation and learning. J. Neurosci. 21, 5222-5228.
Kirschbaum, C., Pirke, K.M., Hellhammer, D.H., 1993. The Trier Social Stress Test - a tool for investigating psychobiological stress responses in a laboratory setting. Neuropsychobiology 28, 76-81.

Kirschbaum, C., Wolf, O.T., May, M., Wippich, W., Hellhammer, D.H., 1996. Stress- and treatment-induced elevations of cortisol levels associated with impaired declarative memory in healthy adults. Life Sci. 58, 1475-1483.

Kudielka, B.M., Hellhammer, D.H., Kirschbaum, C., 2007. Ten years of research with the Trier Social Stress Test - revisited. In: Harmon-Jones, E., Winkielman, P. (Eds.), Social Neuroscience: Integrating Biological and Psychological Explanations of Social Behavior. The Guilford Press, New York, NY, USA, pp. 56-83.

Kuhlmann, S., Piel, M., Wolf, O.T., 2005. Impaired memory retrieval after psychosocial stress in healthy young men. J. Neurosci. 25, 2977-2982.

Kuhlmann, S., Wolf, O.T., 2006. Arousal and cortisol interact in modulating memory consolidation in healthy young men. Behav. Neurosci. 120, 217-223.

Lang, P.J., Bradley, M.M., Cuthbert, B.N., 2008. International Affective Picture System (IAPS): Affective Ratings of Pictures and Instruction Manual. University of Florida, Gainesville, FL, Technical Report A-8.

LeDoux, J.E., 2000. Emotion circuits in the brain. Annu. Rev. Neurosci. 23, 155-184.

Luck, S.J., 2005. An Introduction to the Event-related Potential Technique. The MIT Press, Cambridge.

Lupien, S.J., Gaudreau, S., Tchiteya, B.M., Maheu, F., Sharma, S., Nair, N.P., Meaney, M.J., 1997. Stress-induced declarative memory impairment in healthy elderly subjects: relationship to cortisol reactivity. J. Clin. Endocrinol. Metab. 82, 2070-2075.

McGaugh, J.L., Roozendaal, B., 2002. Role of adrenal stress hormones in forming lasting memories in the brain. Curr. Opin. Neurobiol. 12, 205-210.

Nater, U.M., Moor, C., Okere, U., Stallkamp, R., Martin, M., Ehlert, U., Kliegel, M., 2007. Performance on a declarative memory task is better in high than low cortisol responders to psychosocial stress. Psychoneuroendocrinology 32, 758-763.

Olofsson, J.K., Nordin, S., Sequeira, H., Polich, J., 2008. Affective picture processing: an integrative review of ERP findings. Biol. Psychol. 77, 247-265.

Payne, J.D., Jackson, E.D., Hoscheidt, S., Ryan, L., Jacobs, W.J., Nadel, L., 2007. Stress administered prior to encoding impairs neutral but enhances emotional long-term episodic memories. Learn. Mem. 14, 861-868.

Payne, J.D., Jackson, E.D., Ryan, L., Hoscheidt, S., Jacobs, W.J., Nadel, L., 2006. The impact of stress on neutral and emotional aspects of episodic memory. Memory 14, 1-16.

Phan, K.L., Wager, T., Taylor, S.F., Liberzon, I., 2002. Functional neuroanatomy of emotion: a meta-analysis of emotion activation studies in PET and fMRI. Neuroimage 16, 331-348.

Pruessner, J.C., Kirschbaum, C., Meinlschmid, G., Hellhammer, D.H., 2003. Two formulas for computation of the area under the curve represent measures of total hormone concentration versus timedependent change. Psychoneuroendocrinology 28, 916-931.

Qin, S., Hermans, E.J., van Marle, H.J., Fernandez, G., 2012. Understanding low reliability of memories for neutral information encoded under stress: alterations in memory-related activation in the hippocampus and midbrain. J. Neurosci. 32, 4032-4041.

Roozendaal, B., McEwen, B.S., Chattarji, S., 2009. Stress, memory and the amygdala. Nat. Rev. Neurosci. 10, 423-433.

Roozendaal, B., McGaugh, J.L., 2011. Memory modulation. Behav. Neurosci. 125, 797-824.

Roozendaal, B., Okuda, S., De Quervain, D.J.F., McGaligh, J.L., 2006. Glucocorticoids interact with emotion-induced noradrenergic activation in influencing different memory functions. Neuroscience 138, 901-910.

Sass, S.M., Heller, W., Stewart, J.L., Silton, R.L., Edgar, J.C., Fisher, J.E., Miller, G.A., 2010. Time course of attentional bias in 
anxiety: emotion and gender specificity. Psychophysiology 47, 247-259.

Schwabe, L., Bohringer, A., Chatterjee, M., Schachinger, H., 2008. Effects of pre-learning stress on memory for neutral, positive and negative words: different roles of cortisol and autonomic arousal. Neurobiol. Learn. Mem. 90, 44-53.

Schwabe, L., Joëls, M., Roozendaal, B., Wolf, O.T., Oitzl, M.S., 2012. Stress effects on memory: an update and integration. Neurosci. Biobehav. Rev. 36, 1740-1749.

Schwabe, L., Wolf, O.T., 2010. Learning under stress impairs memory formation. Neurobiol. Learn. Mem. 93, 183-188.

Schwabe, L., Wolf, O.T., Oitzl, M.S., 2010. Memory formation under stress: quantity and quality. Neurosci. Biobehav. Rev. 34, 584-591.

Smeets, T., Cornelisse, S., Quaedflieg, C.W.E.M., Meyer, T., Jelicic, M., Merckelbach, H., 2012. Introducing the Maastricht Acute Stress Test (MAST): a quick and non-invasive approach to elicit robust autonomic and glucocorticoid stress responses. Psychoneuroendocrinology 37, 1998-2008.

Smeets, T., Otgaar, H., Candel, I., Wolf, O.T., 2008. True or false? Memory is differentially affected by stress-induced cortisol elevations and sympathetic activity at consolidation and retrieval. Psychoneuroendocrinology 33, 1378-1386.

Smeets, T., Wolf, O.T., Giesbrecht, T., Sijstermans, K., Telgen, S., Joëls, M., 2009. Stress selectively and lastingly promotes learning of context-related high arousing information. Psychoneuroendocrinology 34, 1152-1161.

Snodgrass, J.G., Corwin, J., 1988. Pragmatics of measuring recognition memory: applications to dementia and amnesia. J. Exp. Psychol. Gen. 117, 34-50.

van Cauter, E., Refetoff, S., 1985. Evidence for two subtypes of Cushing's disease based on the analysis of episodic cortisol secretion. N. Engl. J. Med. 312, 1343-1349. van Stegeren, A.H., Roozendaal, B., Kindt, M., Wolf, O.T., Joëls, M., 2010. Interacting noradrenergic and corticosteroid systems shift human brain activation patterns during encoding. Neurobiol. Learn. Mem. 93, 56-65.

Watson, D., Clark, L.A., Tellegen, A., 1988. Development and validation of brief measures of positive and negative affect: the PANAS scales. J. Pers. Soc. Psychol. 54, 1063-1070.

Wessa, M., Karl, A., Flor, H., 2005. Central and peripheral psychophysiological responses to trauma-related cues in subclinical posttraumatic stress disorder: a pilot study. Exp Brain Res. 167, 56-65.

Weymar, M., Schwabe, L., Low, A., Hamm, A.O., 2012. Stress sensitizes the brain: increased processing of unpleasant pictures after exposure to acute stress. J. Cogn. Neurosci. 24, 1511-1518.

Wilding, E.L., Ranganath, C., 2012. Electrophysiological correlates of episodic memory processes. In: Luck, S.J., Kappenman, E.S. (Eds.), The Oxford Handbook of Event-related Potential Components. Oxford University Press Inc., New York, pp. 373-396.

Wolf, O.T., 2009. Stress and memory in humans: twelve years of progress? Brain Res. 1293, 142-154.

Wolf, O.T., Schommer, N.C., Hellhammer, D.H., McEwen, B.S., Kirschbaum, C., 2001. The relationship between stress induced cortisol levels and memory differs between men and women. Psychoneuroendocrinology 26, 711-720.

Zoladz, P.R., Clark, B., Warnecke, A., Smith, L., Tabar, J., Talbot, J.N., 2011. Pre-learning stress differentially affects long-term memory for emotional words, depending on temporal proximity to the learning experience. Physiol. Behav. 103, 467-476.

Zoladz, P.R., Warnecke, A.J., Woelke, S.A., Burke, H.M., Frigo, R.M., Pisansky, J.M., Talbot, J.N., 2013. Pre-learning stress that is temporally removed from acquisition exerts sex-specific effects on long-term memory. Neurobiol. Learn. Mem. 100, 77-87. 